\title{
Goal-Setting as a Motivational Factor Helping FL Learners in Gaining Their Levels of FL Proficiency
}

\author{
Patrycja Orzechowska, Krzysztof Polok \\ University of Bielsko-Biala, Bielsko-Biala, Poland \\ Email: amy19@op.pl,sworntran@interia.pl
}

How to cite this paper: Orzechowska, P. and Polok, K. (2019) Goal-Setting as a Motivational Factor Helping FL Learners in Gaining Their Levels of FL Proficiency. Open Access Library Journal, 6: e5307. https://doi.org/10.4236/oalib.1105307

Received: March 4, 2019

Accepted: March 26, 2019

Published: March 29, 2019

Copyright $\odot 2019$ by author(s) and Open Access Library Inc.

This work is licensed under the Creative Commons Attribution International License (CC BY 4.0).

http://creativecommons.org/licenses/by/4.0/

\section{(c) (i) Open Access}

\begin{abstract}
The purpose of this research was to check whether goal-setting increases students' motivation and improves their academic achievement. We checked whether students are familiar with the strategy of Goal-Setting, use it in practice and whether there is a connection between students' improvement when it comes to their grades when Goal-Setting is used and when it is not used. We also examined which type of motivation, intrinsic or extrinsic, increases together with raised amount of Goal-Setting strategies used. As far as the motivation is concerned, we checked what type of motivation is $3^{\text {rd }}$ grade Secondary School students driven by. Moreover, we examined whether setting goals and working on achieving them increases students' motivation. The results showed that there existed a high relationship between Goal-Setting and students' motivation toward learning a foreign language. Moreover, Goal-Setting results in the increase of learner's grades. Based on the results, implementing Goal-Setting strategies into the process of teaching and learning was recommended as a tool to enhancing learners' academic performance especially in English Language.
\end{abstract}

\section{Subject Areas}

Education

\section{Keywords}

Motivation, Goal-Setting, FL Proficiency, Academic Achievements, Learner Assessment

\section{Introduction}

Learner motivation is considered as probably the most important part of the 
whole learning process. [1] states that motivation determines one's failure or success when it comes to foreign language acquisition. Inherently, acquiring knowledge is a challenging and hard work. In order to learn, one needs to push their brain to the limits, and this cannot happen without one's being appropriately motivated to do that. Students who are highly motivated learn readily and consider every class as a new, precious experience. On the other hand, unmotivated students find learning frustrating and painful. As a result, they do not put much effort in their learning process, get distracted quickly and learn very little.

Students differ in their levels of motivation and approaches towards learning. It has been claimed [2] that more learners are motivated extrinsically than extrinsically and-as [3] see that-that the current type of motivation largely depends on the form of education offered to the students. [4], following the theories of BICS and CALP offered by [5]. Besides this approach, [6], indirectly indicates that the forms of language-based classroom education exert a strong imprint on the ways foreign language (FL) learners are motivated. Thus, as it seems, what ought to be carefully examined are different learner attitudes, as well as-resulting from them-theories and models of motivation, so as to find out why and in which circumstances some students easily succeed in achieving their learning goals while some others struggle with every single step made toward fulfilling their aspirations.

\section{Motivation and Goal-Setting Interdependence}

In order to maintain a high level of motivation, learners need to be appropriately instructed. According to [7], here the teacher is as important an educational component as the students' forms of motivation. Thus, following [8] [9] or [10], providing students with effective learning strategies lies-in many classroom situations-in teachers' hands. Motivating learning is undoubtedly a central element when it comes to good teaching. As individuals vary, a good instructor ought to focus on students' personal relevance and interests, provide the learners with choice and control over the learning process and ensure each student that with appropriate amount of effort and persistence, everyone can master the material and achieve success in foreign language acquisition. Therefore, in this paper we will make an attempt to analyze and discuss the influence of the teacher in the classroom, the ways of creating appropriate motivational conditions, the process of generating students' motivation and the techniques used to maintain it at a high level.

If a learner wants to succeed, they not only need an optimal amount of motivation, but also ought to be able to set goals. Without appropriately set goals, learners' lack direction and the educational focus. Setting goals allows students to take control of the direction of their learning processes and serves as a benchmark to determine whether one is actually making progress. Thus, it seems out of the question that most (if not all) of the forms of motivation observed in FL learners depend on the level of motivation to help the learners that can be found in FL teachers. Assuming that any FL teacher wants to help their 
learners to learn the language just because s/he has been appointed to teach them is as groundless as an assumption that any FL learner is able to produce their pro-language motivation without any whatsoever external impulse ${ }^{1}$.

Motivation refers to the learners' attitude to the whole process of learning. So as to be successful, students need to become aware and active in their learning. Many university and secondary school learners have remained passive students, aiming towards getting good marks rather than really acquiring the language. Motivated students perceive their foreign language in terms of its practical application. They are able to use their knowledge in practice, develop their knowledge using various available sources like the Internet and literature. According to [11], learner responsibility, independence and choice relate to the level of learner autonomy in language learning. Moreover, motivation is related to students taking responsibility for their learning and development. Both learners' learning failures and successes are attributed to the effort they put into the learning process. Autonomy makes individuals prepared for life-long studying, improves the quality of the language acquisition and allows learners to make use of their learning opportunities not only in the classroom but also outside of it. Regardless of the students' capacity, they are not likely to develop autonomy if they are not truly willing to become responsible for their own learning. Taking charge of our development and accepting full responsibility for our learning/acquisition processes remains the first step towards becoming an autonomous learner. Students ought to understand that the success in learning is dependent crucially on our own choices and actions rather than these suggested by other people's. [12] claims that analyses and reflection abilities enable us to plan out learning, monitor and evaluate it in a deliberate, systematic way. That is why autonomy is the key factor when it comes to students' achievement and motivation as autonomous learners automatically become motivated learners. [13] definition also entails that learners who are autonomous are able to freely apply their skills and knowledge outside of the classroom and develop their knowledge according to their own needs and interests ${ }^{2}$.

Goal-setting is broadly defined as the process of establishing usable and clear objectives, or targets, for learning. According to the Goal Theory offered by [14], students can adopt one of the two general goal orientations: a task-focused one where the focus on learning is intrinsic and an the ability-focused one where the focus on learning is extrinsic. Leaders in goal-setting research and theory, [16] ${ }^{1}$ This, definitely, is a topic for a separate paper. A discussion that a student's FL education is very closely connected with the type of attitude to the performance of the teaching processes their teachers may have, actually has not found its appropriate place in the very process of educational glotto-analysis yet. It has been assumed that any FL teacher wants (and knows how) to perform the whole teaching process and thus appropriately influence their learners' motivation. In this vein, there has appeared a dogma, that any FL learner, while learning a FL language, does want to learn it, what seems to be an assumption loosely grounded in the everyday observation of FL classes and the ongoing behavior of their participants. What is being claimed in this paper is that goal-setting, which undoubtedly influences and creates the whole spectrum of FL learners' educational activities, fully depends on the teacher's approach to help the learners do that.

${ }^{2} \mathrm{~A}$ suggestion on how to possibly arrive at the desired level of autonomy in FL education can be found in the research proposal formed by [15], pp. 36-42. 
are responsible for incorporating almost 400 research works about setting goals into theory of task performance and goal-setting. According to their findings, we can distinguish between two main cognitive determinants which influence behavior: intentions (goals) and values. According to [16] goals highly affect behavior in many meaningful ways. For instance, goals lead to higher effort, mobilize energy and direct attention and action. Goals also motivate learners to develop new useful strategies which may enable them to get to their learning targets. Once the goal is achieved, a learner experiences feelings of satisfaction and further motivation.

According to the research discoveries offered by [17] [18] or [23], autonomy is defined as "[one's] ability to take responsibility for one's learning". Thus, autonomy is considered to be a long-term educational goal, as well as one of the main factors of learning a language successfully. Autonomous, self-regulated learning is now being emphasized especially because of the student-centered paradigm of current education [19]. [5] [17] argued that students are not innately autonomous, but they develop this ability through their training. Thus, teachers should be able to focus on teaching learners appropriate strategies of learning and ways of using them.

As observed by [20], goal-setting is one of the strategies of language learning which can largely encourage learners' autonomy. Numerous studies (e.g., [12] [21] [22] and many others) show that goal-setting positively influences students' performance and enhances their achievement. It has been found that appropriately organized goal-setting, together with specific forms of feedback, lead to better performance, higher achievement and self-regulation and increased level of self-efficacy. Despite that, this learning strategy is being largely neglected and ignored in classrooms. According to [23] 85\% of the polled students, when they were asked if they had been taught goal-setting in schools, denied being exposed to such an activity. One of possible reasons of this fact may be FL teachers' unawareness on how to shape and influence the whole process of FL education of their students ${ }^{3}$.

It is worth emphasizing that goal-setting alone does not necessarily improve students' achievements. Numerous important factors, together with effective goal properties, need to be taken into consideration. [24] state that there are various models related to quality goals, i.e. specificity, proximity and difficulty. Apart from that, [2] also claims that the more challenging a goal is, the higher results students achieve.

\section{The Research}

\subsection{Objectives of the Research}

This quantitative research we planned consists of three parts. First of all the

${ }^{3}$ As it seems, a belief that FL learners have to learn the language because they are aware of the fact they need it in their future life is, in many situations, a wishful thinking only; as [23] research indicates, in many instances FL learners need a more argumentative help than their teachers' belief that they learn because they want to. 
learners will be asked preliminary questions about the amount of time they have possibly spent abroad, the number of additional English lessons they may have attended and the ways of using the English language outside of the classroom. Secondly they will be requested to fill the questionnaire aimed at measuring the level of learners' intrinsic and extrinsic motivation. Finally, they will be measured (with the help of another questionnaire) their intrinsic ability to set goals in learning a FL learning.

The whole research includes three research questions. The first research question is concerned with the relationship of the use of goal-setting and learners' motivation. The question checks whether the students are more motivated when they set themselves goals and whether goal-setting results in the increase of their intrinsic motivation. Our assumptions related to the question are as follow: /a/ the use of goal-setting results in students' increased motivation and /b/ goal-setting increases learners' intrinsic motivation rather than extrinsic motivation.

The second research question examines the connection between the use of goal-setting and learners' grades. The question checks whether students who use the strategy of goal-setting generally get better marks than those who do not implement the aforementioned strategy into the process of learning English as a foreign language. Moreover, the question's aim is to find out whether the use of goal-setting results in the actual improvement in learners' grades when the marks from the previous semester and the grades learners anticipate to get at the end of the current semester are compared. Based on the question, two hypotheses were suggested: /a/ students who implement goal-setting into the process of learning English as a foreign language get better marks than those who do set themselves goals; and / b/ the use of goal-setting results in improvement of learner's grades when the marks from the previous semester and the grades learners anticipate to get at the end of the current semester are compared.

The third research question checks the variables, such as the amount of time the students' have spent abroad, the number of additional English classes and the number of the learners' ways of using English outside of the classroom and their influence of students' academic achievement. Our assumptions are that: /a/ the more time the learners have spent abroad, the better marks they get; /b/ the more additional English classes students attend, the better grades they have; and /c/ the more different ways of using the English language outside of the classroom students implement, the better their marks are.

\subsection{Participants}

The research sample for the study consists of one hundred $3^{\text {rd }}$ grade secondary school learners in a middle-size town in Southern Poland. One of the principal reasons for having chosen this school located in a small town in southern Poland is the fact that it has been recognized as having received considerable achievements in FL education in the whole Small Poland Province. The students learn English as the second language and face their preparation for the school gradua- 
tion exam. This specific group of learners was also chosen because they are thought to be mature and responsible for their own learning targets and goals so their answers are expected to be honest and reliable (which is necessary to come to the credible data). Moreover, young adults seem to have already gained understanding of the seriousness of the concept of motivation and setting goals, so they are familiar with the terms and have some experience with implementing goal-setting into their learning process.

\subsection{Instruments}

The research tool used for the study is the questionnaire which consists of three parts. The specifics of the questionnaire are as follow:

1) The first part is devoted to information about students related to their experience with English as a foreign language and its' use outside of the classroom. Moreover, this part of the questionnaire includes information about students' grades from the previous semester and the grade they anticipate to get at the end of the current semester.

2) The second part of the questionnaire consists of ten question which intend to measure types of learners' motivation. The first five questions are related to learners' intrinsic motivation whereas the remaining five questions are concerned with students' extrinsic motivation.

3) The third and the last part of the questionnaire consists of 18 questions related to the learners' use of the strategy of goal-setting.

\subsection{Procedure}

As specified above, the research was done in a grammar school in a middle-size town in Southern Poland. It took fifteen minutes to complete the questionnaire sheets. The survey was gathered right after the learners had completed answering and checking the questions. The study took place on January $5^{\text {th }}, 2017$. Just as we had expected, we collected 100 surveys altogether. Subsequently, the whole research was elaborated statistically.

\subsection{Results and Discussion}

The first research question: Does the use of Goal-Setting increase students motivation toward learning English as a foreign language? focused on two assumptions. The first assumption checked whether the use of goal-setting increases students' FL motivation, whereas the second referred to the question whether goal-setting influences learners' willingness to FL learning by increasing their intrinsic motivation rather than the extrinsic one.

As far as the results are concerned, the correlation between the level of learners' goal-setting abilities and their level of motivation was moderately positive ( $\mathrm{r}$ $=0.468)$. According to the results, we concluded that goal-setting increases learners' motivation towards learning English as a foreign language. Students who set themselves both short-term and long-term goals appear to be more 
committed to the process of learning, more persistent and responsible for their own learning progress. Goals make secondary school students aware of the benefits of the foreign language acquisition and make them more willing to take control over their own development.

The second assumption of the first research hypothesis was: Goal-setting increases learners' intrinsic motivation rather than extrinsic motivation and aimed at checking whether setting goals increases learners' own willingness toward FL learning, thus not only making them more aware of the necessity of taking responsibility for the learning process, but also increasing their intrinsic motivation at the same time. In order to find out whether the assumption is correct, we correlated the students' levels of goal-setting with their levels of intrinsic as well as extrinsic motivation separately. We were moderately surprised after we had found that the correlation between students' levels of goal-setting abilities and their extrinsic motivation were not only lower than in the case of the intrinsic one, but were highly negative $(r=-0.756)$. According to that, we came to the conclusion that the increased use of goal-setting strategies negatively influences their level of extrinsic motivation by decreasing it. In order to find out whether the above assumption was correct, we correlated the learners' level of goal-setting and their level of intrinsic motivation. The results of our calculations proved that there exists a highly positive correlation between the two variables $(\mathrm{r}=0.811)$. Basing on the results we concluded that the second assumption of the first research question is correct. The learners, who set themselves learning goals according to their personal needs and their own interests are more likely to develop positive motivation to engage in learning because they find it intrinsically rewarding. The students who implement goal-setting strategies turn out to be driven by internal rewards connected with learning English as a foreign language and develop responsibility for their own learning progress. Such students also consider the process of learning enjoyable and are more likely to achieve success in the academic field.

Our second research question was Does the use of Goal-Setting result in the improvement of learners' grades? And it focused on the two hypotheses: Students who implement Goal-Setting into the process of learning English as a foreign language get better marks than those who do not set themselves goals and The use of goal-setting results in improvement of learner's grades when the marks from the previous semester and the grades learners anticipate to get at the end of the current semester are compared. This research question aimed to check whether there exists a positive relation between learners' use of goal-setting strategies and their academic achievement.

In order to find out whether the first hypothesis is correct, we calculated the mean from both the grades students received at the end of the previous semester and the grades students expect to be given at the end of the current semester. Next, we correlated the students' levels of goal-setting abilities and means of their grades. The results showed that there exists a positive relation between the two variables and we can claim that the use of goal-setting strategies in the 
process of the English language acquisition results in the improvement of the learners' grades. The students who set themselves learning goals work hard in order to achieve them. Goal-setting positively influences one's grades no matter if they set short-term or long-term goals. If a student aims towards short-term ones, they might want to complete an assignment on time, get a grade from active participation in a lesson or simply pass a test. In the case of long-term goals, one might want to successfully pass a final exam, get a well-paid job or be able to successfully communicate with foreign language speakers. Both cases require learning systematically and result in developing one's knowledge on a daily basis.

In order to find out whether our second hypothesis was correct, the students' grades from the previous semester and the grades students anticipate to get at the end of the current semester were analyzed. Next, we focused only on the learners who anticipated improvement in their grades. 29 students in total were taken into account. Basing on the data gathered previously, we constructed a graph presenting the level of goal-setting abilities of the aforementioned learners. According to the results, high level of the use of goal-setting strategies is very influential when it comes to one's improvement, as the students who claimed that they would improve their grades had high levels of goal-setting abilities which ranged from 3 to 5 points. Only 4 learners out of 24 did not use goal-setting strategies actively and their level was placed between 1 and 2 points. Basing on the results, we came to the conclusion that when goal-setting strategies are used, students are very likely to make progress in acquiring English as a foreign language. Although 29 students make less than a half of the total number of participants of our study, we assume that, in fact, many more learners actually would improve when both semesters are taken into consideration. Not all of the students are usually aware of their progress and some of them simply do not believe in their abilities. This might be the reason why only one third of the learners admitted that they expected to be given better marks next term. Those students revealed very high levels of goal-setting abilities, so it might be possible that many more students with similar levels of this ability could eventually see their grades improved.

Our third research question Do variables, such as visiting a foreign language speaking country, attending additional classes and using English out of the classroom environment result in the increase of students academic achievement? focused on the relationship between the three aforementioned variables and the students' grades. In order to find out whether our assumptions were correct, we correlated the variables with the students' means of grades.

The first hypothesis of this question was The more time the learners have spent abroad, the better marks they get. This hypothesis required checking how much time the learners were able to have spent in an English-speaking country over the last ten years. We decided to focus on the period of the past ten years only because we assumed that earlier visits would not make any influence on the learners' development, as they were too young to acquire a significant amount of 
knowledge then. According to the results, most of the students declared to have spent from 1 to 20 weeks abroad. There were 6 learners whose visits lasted 40 to 60 weeks and only 2 students whose trips lasted almost 100 weeks in an English-speaking country. The correlation of the variables revealed a weak positive relationship between the amount of time spent broad and learners' academic achievement $(r=0.294)$. Basing on that, we can claim that a visit in an English-speaking country positively influences the process of learning. This might result from several reasons. First of all, a person who is exposed to a foreign language and culture, acquires both of them subconsciously. They need to make use of their already existing knowledge and learn new vocabulary fast so as to be able to carry out a conversation when strolling up a street, buying something in the shop or having nice time any other social place. Reading road signs, newspapers and other writings also create an opportunity to work out the meanings of unknown words and remember them. Such strategies are useful in school environment where reading between the lines, guessing and being spontaneous in making conversation is required. What is more, a visit to a foreign language country gives the process of learning a clear purpose. Students who have been abroad know that they learn in order to be able to communicate with foreign language speakers.

The next hypothesis The more additional English classes students attend, the better grades they have aimed to check whether the additional classes actually positively influence students' academic achievement. The data we collected revealed that the learners often attend such English classes. However, the correlation of the variables showed that the relationship between them is not as strong as it was expected $(r=0.197)$. Despite the fact that the correlation is positive, we assumed that students' mean of grades should raise accordingly to the amount of time the learners spend on studying. We can draw several conclusions from the results. First of all, learning English additionally out of the classroom environment is helpful when it comes to developing and broadening the knowledge. Attending such classes creates an opportunity to learn new, unknown vocabulary, revise the material, better prepare for tests and develop one's knowledge. Regular tutorials might lead to eventual learning progress and improvement of the grades. On the other hand, one has to remember about the reasons for attending such additional classes. And that such classes do not always result in students' increased motivation to learn. Learners who learn with their tutors are very often forced by their parents to do so or their grades are so poor that the school lessons are not enough for them to get satisfying learning results. Despite the fact that students learn regularly, their grades are low because they are not innately motivated towards learning and getting good grades is not meaningful enough to them.

The last research hypothesis was The more different ways of using the English language outside of the classroom students implement, the better their marks are and it was to check if the additional ways of using English chosen by the students influence their academic achievement. While filling in the questionnaire, the 
students were to choose among several ways they could implement such an activity: communicating in English via Skype, using English internet forums, communicating with English-speaking friends, communicating with English-speaking family and/or playing English games. According to the data gathered, most of the learners use English forums. Also, many of them consider playing English games and/or communicating with their English-speaking family members a pleasurable way of developing their foreign language skills. We assumed that the more different ways of using English outside of the school environment learners implement, the better their marks are. The correlation between the variables revealed a strong positive relationship between them $(r=0.595)$. The results of the correlation prove that the number of different ways of using English outside of the classroom exert influence on the students' academic achievement accrodingly. We can draw several conclusions from our calculations. First of all, when students choose their own ways of developing their knowledge which are meaningful to them, they are more likely to make a lot more effort while learning. Reading interesting things on the Internet or talking with the family who speaks a foreign language require developing one's knowledge on their own. Secondly, learning through computer game playing enables students to acuire knowledge subconsciously. The third and the most important thing is the fact that when one chooses a way of learning according to their personal interests and needs, they increase ther intrinsic motivation. Such students see the purpose in language learning, in order to satisfy their own needs and meet their own learning goals.

\section{Conclusion and Educational Implications of Findings}

This study's findings may be useful to the English language teachers in developing effective teaching procedures, strategies and possible materials to be used in class. The results of the research are helpful with understanding the importance, efficiency and effectiveness of implementing goal-setting strategies into the process of learning the English language. Conclusions which were drawn from this study also raise the awareness of motivation as a factor necessary in foreign language acquisition. The combination of both goal-setting and motivation undoubtedly needs to be highlighted in the process of teaching and learning as they serve as a tool which makes foreign language acquisition effective.

\section{Conflicts of Interest}

The authors declare no conflicts of interest regarding the publication of this paper.

\section{References}

[1] Brown, D.H. (2000) Principles of Language Learning \& Teaching. 4th Edition, Longman, New York.

[2] Dörnyei, Z. (2001) Motivational Strategies in the Language Classroom. Cambridge 
Language Teaching Library, Cambridge. https://doi.org/10.1017/CBO9780511667343

[3] Williams, M. and Burden, R. (2005) Psychology for Language Teachers. Cambridge University Press, Cambridge.

[4] Baker, C. (1997) Foundations of Bilingual Education and Bilingualism. 2nd Edition, Multilingual Matters, Clevedon, Philadelphia and Sydney.

[5] Cummins, J. (1984) Bilingualism and Special Education: Issues in Assessment and Pedagogy. Multilingual Matters, Clevedon.

[6] Cummins, J. (1984) Wanted: A Theoretical Framework for Relating Language Proficiency to Academic Achievement among Bilingual Students. In: Rivera, C., Ed., Language Proficiency and Academic Achievement, Multilingual Matters, Clevedon.

[7] Harmer, J. (2001) The Practice of English Language Teaching. Longman, London.

[8] Ushioda, E. (2016) Language Learning Motivation through a Small Lens: A Research Agenda. Language Teaching, 49, 564-577. https://doi.org/10.1017/S0261444816000173

[9] Ushioda, E. and Dörnyei, Z. (2012) Motivation. In: Gass, S. and Mackey, A., Eds., The Routledge Handbook of Second Language Acquisition, Routledge, New York, 396-409.

[10] Wu, Z. (2016) Towards Understanding Interpreter Trainees' (de)motivation: An Exploratory Study. The International Journal for Translation and Interpreting, 8, 13-25.

[11] Dickinson, L. (1995) Autonomy and Motivation a Literature Review. System, 23, 165-174. https://doi.org/10.1016/0346-251X(95)00005-5

[12] Edwins, S.D. (1995) Increasing Reflective Writing and Goal-Setting Skills on High Ability Sixth Grade Mathematics Students. ERIC Database (ED392065).

[13] Holec, H. (1981) Autonomy in Foreign Language Learning. Pergamon, Oxford.

[14] Dweck, C.S. (1986) Motivational Processes Affecting Learning. American Psychologist, 41, 1040-1048. https://doi.org/10.1037/0003-066X.41.10.1040

[15] Webster, A., Beveridge, M. and Reed, M. Managing the Literacy Curriculum; How Schools Can Become Communities of Readers and Writers. Routledge, London, New York.

[16] Locke, E.A. and Latham, G.P. (1990) A Theory of Goal Setting and Task Performance. Prentice Hall, Upper Saddle River.

[17] Benson, P. (2001) Teaching and Researching Autonomy in Language Learning. Longman/Pearson Education, Harlow.

[18] Dickinson, L. (1987) Self-Instruction in Language Learning. Cambridge University Press, Cambridge.

[19] Scharle, A. and Szabo, A. (2000) Learner Autonomy: A Guide to Developing Learner Responsibility. Cambridge University Press, Cambridge.

[20] Wentzel, K.R. (1991) Social Competence at School: Relations between Social Responsibility and Academic Achievement. Review of Educational Research, 61, 1-24.

[21] Boekaerts, M. (2002) Motivation to Learn. Educational Practice Series. International Bureau of Education, Geneva.

[22] Griffee, D.T. and Templi, S.A. (1997) Goal Setting Affects Task Performance. ERIC database (ED413782).

[23] Bishop, J. (2003) Empowering Students to Succeed. NCSC News. http://www.ncsc.info 
[24] West, R.L. and Thorn, R.M. (2001) Goal Setting, Self-Efficacy, and Memory Performance in Older and Younger Adults. Experimental Aging Research, 27, 41-65. https://doi.org/10.1080/036107301750046133 